\title{
The challenge of consent in clinical genome-wide testing
}

\author{
Katherine Burke, Angus Clarke
}

Institute of Medical Genetics, University Hospital Wales, Cardiff, UK

Correspondence to $\mathrm{Dr}$ Katherine Burke, Paediatric Registrar and Wellcome Fellow in Society and Ethics, Institute of Medical Genetics, University Hospital Wales, Heath Park, Cardiff CF14 4XW, UK; katherine.burke@doctors.net.uk

Received 26 November 2015 Revised 5 April 2016 Accepted 6 April 2016 Published Online First 28 April 2016

\section{ABSTRACT \\ Genome-wide testing methods include array comparative genomic hybridisation $(\mathrm{aCGH})$, multiple gene panels, whole exome sequencing (WE) and whole genome sequencing (WGS). Here we introduce some of the key ethical and social considerations relating to informed consent for the testing of children, particularly the management of incidental findings and variants of unknown significance.}

\section{INTRODUCTION}

General paediatricians, neonatologists and other non-genetic specialist clinicians now carry out genomic investigations in children. The rapid implementation of new genomic technologies means clinicians are required to have the knowledge and the confidence to allow the discussion of testing and its potential implications with parents and families. Following the introduction of array comparative genomic hybridisation $(\mathrm{aCGH})$ as a clinical investigation, studies looking at paediatricians suggested that such non-genetics professionals often lack the knowledge and confidence to provide an explanation of the proposed genetic investigation, as a necessary preliminary to consent. ${ }^{12}$ When comparing clinicians' confidence in sharing results with patients and families following aCGH testing, paediatricians self-reported low confidence in describing pathogenic results and variants of unknown significance. Many also did not consider it pertinent-or their role-to discuss the potential for revealing misattributed paternity and predisposition to adult-onset disease. ${ }^{3}$

Confidence in describing and managing the results of aCGH will have undoubtedly improved with increasing familiarity, use and availability in the clinical setting. However, as sequence-based technologies enter clinical practice, first through research projects, such as the 100000 Genomes Project, ${ }^{4}$ then later as validated clinical investigations, similar issues will be encountered. How can a valid, adequately informed consent be ensured given the volume and complexity of data generated, particularly with regard to incidental findings and variants of unknown significance (see table 1)? It may even be doubted that 'informed consent', as traditionally defined, is attainable in everyday practice. $^{5}$

\section{Incidental (off-target) findings}

Incidental findings (see table 1) can be assessed for reporting according to three criteria: analytical validity, clinical significance and actionability (see table 2). ${ }^{6}$ Yet despite meeting these criteria, we may

\section{Box 1 Case studies}

Case 1 A 4-year-old girl had a whole exome sequence requested by the paediatric neurologist to investigate her complex global developmental delay. When the results showed a chromosome 3p25.3 duplication encompassing exons 2 and 3 of the Von Hippel-Lindau (VHL) gene, she was referred to the clinical genetic service for assessment. $^{8}$

Case $2 \mathrm{~A}$ term infant is 3 days old and is being cared for in the neonatal unit following his birth. Antenatally, he was diagnosed with gastroschisis and complex congenital cardiac anomalies. aCGH (array comparative genomic hybridisation) is used to try and establish a genetic diagnosis. A potentially pathogenic mutation is identified in the BRCA1 gene.

Case 3 A 24-week gestation infant has aCGH performed as part of a small for gestational age assessment. At 1 week, the infant remains unwell with sepsis and necrotising enterocolitis. aCGH reveals a microdeletion associated with increased risk of autism and schizophrenia. The neonatal intensive care unit staff wonder if this should be revealed to the infant's parents for consideration in decision-making about continuation of care. ${ }^{17}$

still question how secondary, incidental or 'offtarget' information is managed in children.

In the example in box $1,{ }^{7}$ the child has been seen by the neurologist due to a delay in her development. Testing has inadvertently revealed a well characterised cancer syndrome: features of the disease can be identified using radiological and biochemical tests many years before the onset of clinical symptoms and with significantly improved prognosis. Onset is in adulthood, so reporting this result does not have implications for Sophie at this time. However, sharing her result may enable other family members to undergo enhanced surveillance or prophylaxis, which could prevent the development of cancer, or enable it to be treated earlier and with improved outcomes, which clearly relates to the best interests of Sophie. Sophie's parents, in allowing the doctors to perform this investigation on Sophie, may well not have considered these potentially wide-ranging consequences of an 'incidental' diagnosis. If they had been given information about possible incidental findings and understood it, would they still have proceeded with testing? - that is, were they adequately informed? When information of potential health or reproductive consequence is discovered, how are 
Table 1 Definitions

\begin{tabular}{ll}
\hline Classification of result & Description \\
\hline $\begin{array}{l}\text { Variation of unknown significance/ } \\
\text { variation of uncertain significance }\end{array}$ & $\begin{array}{l}\text { Genomic alterations-including copy number variations, deletions, duplications-with } \\
\text { unknown phenotypical correlations, or alterations for which the genes involved have not } \\
\text { been described. Can be stratified as likely pathological or likely benign. }\end{array}$ \\
Incidental finding & Pathogenic genomic variation unrelated to the presenting phenotype. \\
\hline
\end{tabular}

decisions about disclosure made by the professionals? Would a decision to reveal information have consequences for Sophie's autonomy? A discussion about informed consent can only begin at this point: when we consider, in context, how the consent is obtained and what it is designed to achieve or enable.

\section{(Informed) consent in practice}

The ethical concept of 'informed consent' consists broadly of two key elements. ${ }^{8}$ Medical professionals must obtain the consent of the individual or their proxy prior to undertaking an investigation or commencing treatment. This consent, however, is meaningless without a sufficient understanding of what is at stake, such as what the proposed investigation or treatment entails, the potential benefits and risks, and reasonable alternatives. The medical professional must ensure that the person who will make the decision (as to whether or not to give their consent) must be adequately informed and the professional must provide sufficient, personally tailored information, in an appropriate format for that individual, to achieve that. The information that is shared is decided upon according to the needs and preferences of the particular patient or family, based on their expressed preferences, and the assessment of the responsible clinical team.

Informational requirements are complex and highly situated in terms of time, place and the individual situation in question. The informational needs of a family whose young child is undergoing investigation for severe impairment, as in case 1, who potentially will not attain medical decision-making autonomy, might differ from those such as the parents in case 2, particularly with regard to the management of incidental or uncertain information.

In this second case, sharing this result may impact adversely on the child's future autonomous decision in adulthood about whether to undergo testing or enhanced screening, when the family history is known. The context is clearly very different when the family is already aware of an important Mendelian genetic risk: in the case of a strong family history of early onset breast cancer, discovery of a genetic mutation accounting for this might well be anticipated. As such, WG/WE approaches must not overlook, or be seen to bypass, the well established norm of deferring predictive testing of children for an already known high risk of an adult-onset disease. ${ }^{9}$

If the family history is unknown, or complex, not revealing the result denies the Mother of the child in case 2, and potentially other relatives, the opportunity to (potentially) benefit from this result: the so-called 'duty to warn'. Indeed, the investigation of a child may be the only way that this important information comes to light. It is therefore considered reasonable that the findings of WG/WE analyses should be pursued when high throughput clinical sequencing takes place and that any significant results should be disclosed to the parents. Where such findings are genuinely incidental and completely unanticipated, the result is not predictive, rather truly opportunistic, and potentially of real benefit to the health of the child and wider family. As such, the individual's right to confidentiality is limited in order to realise the potential of genomic testing for broader public good.

\section{Managing the challenge: various approaches}

Guidance from the American College of Medical Genetics and Genomics (ACMG) caused significant controversy through its attempt to define which mutations found 'incidentally' should be reported to the patients and families. ${ }^{10}$ Rather than dealing with incidental information as it arises ad hoc in the bioinformatic processing of data obtained from WG/WE sequencing, the ACMG approach employs a systematic screening approach on all samples, seeking out clinically important variants in 56 genes relating to 25 disease processes. This selection of loci for screening is based on the ACA (analytical validity, clinical significance and actionability) criteria and includes multiple cancer predisposition syndromes, such as Lynch syndrome or Von Hippel-Lindau syndrome, in addition to familial hypercholesterolaemia and cardiac genetic syndromes such as long QT syndrome, or hypertrophic cardiomyopathy. These results, the ACMG argued, should be revealed regardless of parental preferences regarding secondary findings 'where there is strong evidence that a secondary finding has urgent and serious implications for a child's health or welfare, and effective action can be taken to mitigate that threat'. ${ }^{11}$

European guidance ${ }^{12}$ has supported this position, though it has emphasised 'childhood medical actionability' and avoided

Table 2 Analytical validity, clinical significance and actionability (ACA $)^{6}$

\begin{tabular}{|c|c|c|}
\hline Criteria & Definition & Example \\
\hline $\begin{array}{l}\text { Analytical } \\
\text { validity }\end{array}$ & $\begin{array}{l}\text { Variant is identified using a method that is evidence-based and } \\
\text { of sufficient sensitivity and specificity. }\end{array}$ & $\begin{array}{l}\text { Use of an evidenced method, such as aCGH, WE, WG sequencing, in a laboratory } \\
\text { conforming to quality control standards. }\end{array}$ \\
\hline $\begin{array}{l}\text { Clinical } \\
\text { significance }\end{array}$ & $\begin{array}{l}\text { The health implications of the variant that is identified-is } \\
\text { there a known, reported clinical correlate? }\end{array}$ & BRCA1 and risk of breast cancer. \\
\hline Actionability & $\begin{array}{l}\text { Potential to modify the disease course when the presence of } \\
\text { the variant is known. }\end{array}$ & $\begin{array}{l}\text { Additional screening or prophylaxis, such as serial scanning, or altered reproductive } \\
\text { decision-making — such as preimplantation genetic diagnosis. }\end{array}$ \\
\hline
\end{tabular}

aCGH, array comparative genomic hybridisation; WE, exome sequencing; WG, whole gene. 
references to a broader sense of welfare, which might be used to justify disclosure where incidental findings have potential implications for parents and other relatives. This is indicative of a greater emphasis on autonomy and future autonomy in Europe, as opposed to the deference to parental authority and autonomy of the ACMG.

\section{Autonomy?}

The approach suggested by ACMG could be seen as a call for opportunistic screening, representing an intentional and systematic attempt to identify pathogenic variants in specified genes, unrelated to the reason which prompted testing. This could be seen as at odds with the established professional consensus that testing in childhood for adult-onset disease should be avoided or deferred. ${ }^{9}$ Identifying these 'patients-in-waiting' ${ }^{33}$ can be seen as undermining the child"s future autonomy to decide whether or not to be tested for disease or disease susceptibility and may entail risk of psychological harm when status is prematurely revealed. ${ }^{14}$ Yet respecting the rights of children to 'an open future ${ }^{15}$ can introduce significant moral challenge. Defining the limits of this shared autonomy is difficult: where a high risk is found for an untreatable adult-onset disorder, which may alter the reproductive decisions of parents, should the professionals share this information? While current guidance does not advise that such results about children be returned, some test providers give patients and parents the opportunity to receive predictive information about untreatable adult-onset disorders, ${ }^{16}$ despite the potential for emotional harm and the impact on consequences for future (and current) autonomy.

The role of parental preferences and autonomy is complex. In case 3 (adapted from ref. 17) clinicians question whether decisions regarding the continuation of care for an unwell, preterm infant, might be altered if the parents knew about the presence of a neuropsychiatric susceptibility gene. There may be a divergence in how clinicians and parents feel this information should impact on decision-making, in a context where decisions are highly contextual and within the acceptable zones of parental discretion. Beyond the consideration of gene-environment (GxE) interactions, the failure to acknowledge the likely but still poorly defined role of epigenetic factors limits the recognition of the complexity of this supposed prognostic information.

It is generally acknowledged that competent adults have a right to remain ignorant with regard to genetic information about themselves. ${ }^{18}$ This supports the ethical principle of

Table 3 Proposed minimal requirements for consent in whole genome sequencing ${ }^{22}$

\begin{tabular}{|c|c|}
\hline Scope & The scope of the test \\
\hline Description & Brief description of the test process. \\
\hline Benefit & Benefits that we expect. \\
\hline Risk & Possible disadvantages, risk and complications. \\
\hline Voluntary & Voluntary nature of the test. \\
\hline Refusal & $\begin{array}{l}\text { Possibility of refusal at any time, without consequences for } \\
\text { clinical or social care. }\end{array}$ \\
\hline Alternative test & Description of alternative diagnostic tests, if available. \\
\hline Confidentiality & $\begin{array}{l}\text { Description of the measures taken to ensure confidentiality, } \\
\text { and the privacy of the results now and in the future. }\end{array}$ \\
\hline Future use & $\begin{array}{l}\text { Destination and potential further use of samples, such as } \\
\text { research, retesting with further phenotypical information, } \\
\text { retesting as genomic databases become more extensive. }\end{array}$ \\
\hline $\begin{array}{l}\text { Incidental } \\
\text { findings }\end{array}$ & Management of incidental findings, and right not to know. \\
\hline
\end{tabular}

autonomy, allowing individuals to remain the authors of their own lives. Yet whether this right should extend to parents when children undergo genome-wide testing is unclear: there are different perspectives on this. The informational privacy of children must be balanced with the need for parents to act in the best interests of their children, with beneficence (on the part of the parent, proxy or professional) rather than autonomy acting as the guiding principle. Giving parents the option of not being informed of any clinically relevant findings regarding the health of their child ignores this parental responsibility. ${ }^{19}$ Whether hypothetical 'advance instructions' about how to respond to a range of possible findings would be considered as valid is dubious. Perhaps there is no parental right to ignorance about information that may stubstantially benefit one's child-parents must be seen to act in the best interests of their child, and when they are thought not to be doing so (in conflict with the clinical team), this could constitute a safeguarding concern. To assert the 'right not to know' may be incoherent when it is not yet known that there is anything to (not) know, presenting a challenge to how advance instructions and preferences can be meaningfully established and respected.

\section{Possible solutions}

Clinician-led approaches include attempts to use the model of 'generic' consent. ${ }^{19}$ By providing information in general categories, the aim is to avoid the unhelpful-indeed potentially paralysing-effects of information overload, while still providing sufficient information for the making of decisions. ${ }^{20}$ Largely these attempts have been based around a categorical approach to unanticipated findings, based around clinical actionability. Adopting this approach, results of unknown clinical significance would not be reported. This acknowledges the anxietyprovoking and time-consuming nature of discussing vast numbers of variants of unknown or uncertain significance, recognising that it may not be possible to report every potential finding. The acceptability of this to parents, and to patients themselves, has yet to be explored in practice, but such clinician-led filtering could be represented as a return to medical paternalism that disempowers families and patients. The role of parents and carers in defining the types of results that might be reported back to them is starting to be explored. As indicated above, however, the value of hypothetical decisions, made in advance, is unclear.

Highlighting the proposed benefits of a test provides a useful starting point from which to explore the key issues when performing genome-wide investigations. Describing the potential categories of results allows clinicians and parents to be clear about the types of information genomic tests can generate. Proposed minimal requirements for consent ${ }^{21}$ when wholegenome sequencing is undertaken in the clinical setting are helpful (see table 3). However, defining the 'disadvantages, risks and complications' remains vague and offers little support to non-genetics clinicians about the sort of issues we should highlight and discuss in the clinical setting when testing is being considered and undertaken. While empirical evidence about the informational needs of families undergoing whole-genome sequencing is awaited, it would seem prudent to provide information about the risk of incidental findings, variants of uncertain significance and the potential need for the testing of family members, particularly the parents and siblings of the index case, and including the potential for identifying misattributed paternity. Parental samples are required for the interpretation of aCGH data in $10 \%$ of cases $^{22}$ and this is likely to be much greater in WG or WE sequencing. Where laboratories employ 
Box 2 Points to consider in consent for genome-wide tests

Family history-consider potential known or likely genetic disease

Describe the method being used - aCGH (array comparative genomic hybridisation), multigene panel, WE, WG

Broad description of categories of results - pathogenic, benign, incidental findings, variants of unknown significance

Potential need for (biological) parental samples to understand implication of variant

Potential future recontact as genetic knowledge and understanding improves

Use of structured consent forms and information leaflets and resources to support information sharing and decision-making

ACMG guidance and systematically 'search' for off-target findings, this should be discussed and explained clearly. When parents themselves are undergoing testing to ascertain the potential meaning of a result in a child, the implications of revealing, or systematically analysing off-target secondary variants must also be emphasised and considered.

As more genomic sequencing is performed, our ability to interpret findings, relating genotypical information to potential phenotypes, will continue to improve and develop. Interpretation depends heavily on publicly available genomic databases, which are continually updated with increasingly comprehensive data. It has been argued that clinicians have a responsibility to recontact patients when new information, regarding the interpretation of genetic information, becomes available. ${ }^{23}$ No consensus currently exists about how this should be managed, and addressing such concerns is likely to be particularly challenging in the paediatric setting: how should information be communicated to children gaining competency and autonomy with regard to their own health? Any duty to recontact children in adulthood, to ensure the appropriate communication of results or to reconsider the significance of variants of unknown significance in the light of new information, would be challenging from logistical, economic and legal perspectives. ${ }^{24}$ However it is important that families are aware that the implications of information they receive may change over time.

\section{Conclusion and future work}

As genetic investigations move from the specialist to the general medical setting, clinicians must be confident in supporting patients and parents to achieve an adequate understanding to enable them to benefit from new genetic technologies. A reasonable approach has to be developed that neither denies patients access to an important diagnostic tool because families are deemed to have inadequate understanding, nor restricts the mainstreaming of genomic medicine by making clinicians feel that the demands of informed consent are impossible to fulfil. Parents (and patients too, where feasible) need a pragmatic understanding that genomic testing might yield clear diagnostic information, it might add nothing, it might identify a genetic change of uncertain significance or it might, indeed, identify an incidental finding of unexpected significance with consequences for the child and family more broadly. It is also important to consider the special circumstances of certain specific groups, for example those participating in clinical research such as the 100000 Genomes Project ${ }^{4}$ where raw data might be made available, and children who are, or may in the future be, fostered or adopted. $^{25}$

Continuing association with clinical genetics services will facilitate clinical support in complex cases, strengthening communication and education as technologies and practices develop. Interdisciplinary empirical research into the situated bioethical considerations that arise will be important and will inform policy decisions about how best to support the informational needs of patients, families and children undergoing testing.

Twitter Follow Katherine Burke at @drkneely

Contributors $\mathrm{KB}$ had primary responsibility for conceiving this paper, reviewing the literature, writing the first draft and editing the manuscript. AC contributed to the analysis, provided feedback on drafts and supports the final version.

Funding $K B$ is supported in this work by a Wellcome Fellowship for Healthcare Professionals (Society and Ethics).

Competing interests None declared.

Provenance and peer review Commissioned; externally peer reviewed.

\section{REFERENCES}

1 Rosas-Blum E, Shirsat $P$, Leiner M. Communicating genetic information: a difficult challenge for future pediatricians. BMC Med Educ 2007;7:17.

2 Kegley J. An ethical imperative: genetics education for physicians and patients. Med Law 2003;22:275-83.

3 Reiff M, Ross K, Mulchandani S, et al. Physicians perspectives on the uncertainties and implications of chromosomal microarray testing of children and families. Clin Genet 2013;83:23-30.

4 https://www.genomicsengland.co.uk/the-100000-genomes-project/ (accessed 17 Mar 2016).

5 Dondorp W, De Wert G. The 'thousand-dollar genome': an ethical exploration. The Hague, the Netherlands: Health Council of the Netherlands. 2010. http:// www.gezondheidsraad.nl/sites/default/files201015E.pdf (accessed 9 Sep 2013).

6 Knoppers BM, Zawati MH, Sénécal K, et al. Return of genetic testing results in the era of whole-genome sequencing. Nat Rev Genet 2015;16:553-9.

7 Crawford G, Foulds N, Fenwick A, et al. Genetic medicine and incidental findings: it is more complicated than deciding whether to disclose or not. Genet Med 2013;15:896-9.

8 Beauchamp TL, Childress JF. Principals of biomedical ethics. Oxford, UK: OUP 2009.

9 Clarke A. The Genetic Testing of Children. Working Party of the Clinical Genetics Society (UK). J Med Genet 1994;31:785-97.

10 Green RC, Berg JS, Grody WW, et al. ACMG Recommendations for reporting of incidental findings in clinical exome and genome sequencing. Genet Med 2013:15:565-74

11 Botkin JR, Belmont JW, Berg JS, et al. Points to consider: ethical, legal, and psychosocial implications of genetic testing in children and adolescents. Am J Hum Genet 2015;97:6-21.

12 Van El CG, Cornel MC, Borry P, et al., on behalf of the ESHG Public and Professional Policy Committee. Whole-genome sequencing in health care: recommendations of the European Society of Human Genetics. Eur J Hum Genet 2013:21:580-4.

13 Timmermans S, Buchbinder M. Patients-in-waiting: living between sickness and health in the genomics era. J Health Soc Behav 2010:51:408-23.

14 Malpas JP. Predictive genetic testing of children for adult-onset diseases and psychological harm. J Med Ethics 2008;34:275-8.

15 Feinberg J. The child's right to an open future. In: Aiken W, Lafollette $\mathrm{H}$, eds Whose child? Children's rights, parental autonomy, and state power. New Jersey: Littlefield, Adams and Co, 1980:124-53.

16 Netzer C, Klein C, Kohlhase J. New challenges for informed consent through whole genome array testing. J Med Genet 2009;46:495-6.

17 Wilkinson D, Barnett C, Savulescu J, et al. Genomic intensive care: should we perform genome testing in critically ill newborns? Arch Dis Chil Fetal Neonatal Ed 2016;101:F94-8.

18 Wilson J. To know or not to know? Genetic ignorance, autonomy and paternalism. Bioethics 2005; 19:492-504.

19 Dundorp W, Sikkema-Raddatz B, de Die-Smulders C, et al. Arrays in postnatal and prenatal diagnosis: an exploration of the ethics of consent. Hum Mutat 2012;6:616-22 


\section{Review}

20 Berg JS, Khoury MJ, Evans JP. Deploying whole genome sequencing in clinical practice and public health: meeting the challenge one bin at a time. Genet Med 2011;13:499-504.

21 Ayuso C, Millán JM, Mancheño M, et al. Informed Consent for whole genome sequencing studies in the clinical setting. Proposed recommendations on essential content and process. Eur J Hum Genet. 2013;21:1054-9.

22 Darilek S, Ward P, Pursley A, et al. Pre- and postnatal genetic testing by array-comparative genomic hybridization: genetic counseling perspectives. Genet Med 2008:10:13-18.
23 Sharpe RR. Downsizing genomic medicine: approaching the ethical complexity of whole-genome sequencing by starting small. Genet Med 2011;13:191-4.

24 Pyeritz RE. The coming explosion in genetic testing - is there a duty to recontact? N Engl J Med 2011;365:1367-9.

25 Parker MJ, Teasdale K, Parker MJ, et al. The genetic assessment of looked after children: common reasons for referral and recent advances. Arch Dis Child 2016;101:581-4. 


\section{ADC The challenge of consent in clinical genome-wide testing}

Katherine Burke and Angus Clarke

Arch Dis Child 2016 101: 1048-1052 originally published online April 28, 2016

doi: 10.1136/archdischild-2013-304109

Updated information and services can be found at:

http://adc.bmj.com/content/101/11/1048

\section{These include:}

References This article cites 21 articles, 5 of which you can access for free at: http://adc.bmj.com/content/101/11/1048\#BIBL

Email alerting Receive free email alerts when new articles cite this article. Sign up in the service box at the top right corner of the online article.

Topic

Articles on similar topics can be found in the following collections

Collections

Informed consent (60)

Legal and forensic medicine (98)

\section{Notes}

To request permissions go to:

http://group.bmj.com/group/rights-licensing/permissions

To order reprints go to:

http://journals.bmj.com/cgi/reprintform

To subscribe to BMJ go to:

http://group.bmj.com/subscribe/ 